but where abscesses or fistulae are present, these are clear indications for preliminary ileocolostomy with exclusion. It this does not give relief, resection can be done more safely at a second operation.

The danger of the 'blind loop' blowing out following an exclusion operation seems to be more apparent than real, because the deflection of the faecal stream away from the diseased area causes the stricture to relent.

Whatever the form of surgery employed, there is no doubt that the recurrence rate is depressingly high.

\section{Summary}

Crohn's disease is a non-specific granuloma of the gut, commonest in the terminal ileum, sometimes involving other parts.

An acute form of the disease mimics appendicitis and is seldom recognized until the belly is opened. Nothing more should be done; appendicectomy is to be avoided as it may be followed by a fistula.

In its chronic stages the disease presents in many ways, but its important features are chronic small intestine obstruction and the complications of subacute perforation. Operation may be neces- sary, but whatever is done the chance of recurrence is high.

A follow-up study of 26 cases treated at one hospital confirms these generalizations and emphasizes the problem of the recurrent case.

In the chronic phase surgery should be limited to those cases with clear evidence of obstruction, perforation, abscess or fistula formation, or severe intractibility.

I wish to thank Professor R. S. Pilcher for his assistance in preparing this paper, and also the consultant staff of University College Hospital for permission to follow-up their patients.

\section{BIBLIOGRAPHY}

ARMITAGE, G., and WILSON, M. (1950-51) Brit. F. Surg., 38, 183 .

BOCKUS, H. L. (1945), 7. Amer. med. Ass., 127, 449.

CHESS, S., CHESS, D., OLANDER, G., BENNER, W., and COLE, W. H. (1950), Surgery, 27, 221.

COOMBE, C., and SAUNDERS, W. (1813), Med. Trans. Roy. Coll. Phys. Lond., $4, \mathrm{I} 6$.

CROHN, B. B., GINZBURG, L., and OPPENHEIMER, G. D. (1932), F. Amer. med. Ass., 99, 1323.

DALZIEL, T. K. (1913), Brit. med. $\mathcal{F . , ~ 2 , ~} 1068$

FELSEN, J. (1936), Amer. F. Path., 12, 395.

GARLOCK, J. H. (1946), Amer. F. Surg., 72, 875.

HADFIELD, G. (1939), Lancet, ii, 773.

HAWTHORNE, H. R., and FROBESE, A. S. (1949), Ann. Surg., I30, 233.

HOMB, A. (1946), Acta. chir. scand., 94, 343.

KANTOR, J. L. (1934), F. Amer. med. Ass., 103, 2016

PATEY, D. H. (1949), Proc. Roy. Soc. Med., 42, 769.

\title{
THE RESULTS OF OPERATIVE TREATMENT OF PROLAPSE \\ A follow up of 340 cases
}

\author{
By A. P. Bentall, M.A., M.D., M.R.C.O.G., D.C.H. \\ Assistant Obstetrician and Gynaecologist, Norfolk and Norwich Hospital
}

\section{Introduction}

At least twice a week the majority of gynaecologists throughout the country come to the stage in their operating lists where, having taxed themselves with the more exacting problems earlier on, they can sit down to deal with one or two cases of prolapse before the hard part of the morning's work is over. They are justified in expecting that the operation, though it may be tedious, especially to the assistant standing with bent back, will run smoothly and according to the usual routine varied but slightly to suit the particular nature of the case. Their experience teaches them to expect their patients to have some difficulty in passing water for a day or two, to be unable to sit down in comfort for about ten days and to be anxious to return home, usually with thanks for what has been done, at the end of three weeks.

We do not often see a recurrence and when we do the original operation was often done elsewhere and we assume that it was done inefficiently. We feel justified in thinking that the great majority of our own patients get on well and remain eternally grateful, but in reality we know little of the end results of the vast number of operations for prolapse which are done throughout the country every year.

A study of the literature on the subject is not very helpful. Publications on the results have been surprisingly few in recent years and such as are available give a very varied picture of the success which may be expected, the picture usually 
depending on the thoroughness with which the cases were followed up.

In an attempt to ascertain the degree of success which is being achieved the results of 340 cases operated upon in the years $1948-5 \mathrm{I}$ have been studied; 240 of these cases have been treated in an outlying hospital where, in the absence of a resident medical officer, the day-to-day care has been undertaken by local practitioners. The reamining 100 who, by reason of their age or some medical complication, were in need of closer supervision, were treated in the main centre.

Certain conclusions have been reached from the experience gained in the treatment and follow up of these cases and, in view of the paucity of literature on the subject of this everyday operation, they have been recorded.

\section{Symptoms}

The average age of the 340 patients was fiftyone. Although multiparity is usually regarded as a predisposing factor in the production of prolapse, large families seem to be increasingly uncommon even in a rural area such as Norfolk and the average number of children works out at only 3.25 .

The symptoms of which the patient complains vary greatly and bear surprisingly little relationship to the degree of prolapse or anatomical abnormality which is found on examination. Backache, a dragging sensation in the lower abdomen or a feeling of ' something coming down' seem to be the most common presenting symptoms.

The complaint of stress incontinence deserves special consideration. It was confirmed, as was emphasized during the discussion on the subject at the I3th British Congress of Obstetrics and Gynaecology (Jeffcoate, 1949), that the occurrence of this symptom bears little relationship to the degree of prolapse or cystocoele which is present. Stress incontinence was present to the extent of causing notable inconvenience to the patient in 132 cases (39 per cent.). This means that in 207, or 6I per cent., of the cases, all of whom had prolapse of sufficient degree to merit surgical treatment, there was no significant complaint of stress incontinence. The symptom was severe enough to constitute one of the patients' principal complaints in 44 cases ( 1 I per cent.). Seventeen patients, i.e. 5 per cent. of the total number and 12 per cent. of those with any complaint of stress incontinence, suffered from this complaint in a severe degree without any demonstrable uterine prolapse or cystocoele.

Complete procidentia, often with accompanying ulceration, was present in $4 \mathrm{I}$ cases (I I per cent.). The age incidence and parity of these cases was above the average, being sixty-three and 4.5 years, $\frac{\varrho}{3}$ respectively.

Certain associated medical conditions were encountered relatively frequently. Visceroptosis $\stackrel{c}{\Rightarrow}$ of sufficient degree to justify the wearing of a $\overrightarrow{\vec{s}}$ special belt was noted 27 times at the initial examination. Functional uterine haemorrhage was present in 20 cases and fibroids in 6, although $\overline{\bar{\omega}}$ this condition is not common in multiparous $\widehat{\Phi}$ women. Prolapsed piles sufficiently severe to merit surgical treatment were seen in 12 cases. Some degree of hypertension was common, but $\vec{O}$ was sufficiently severe to call for special con- $\overrightarrow{\vec{H}}$ sideration by the anaethetist on 12 occasions. $\vec{\omega}$ Diabetes called for special supervision in 9 cases. Operation was contraindicated by cardiac failure 3 in I case and by arthritis so severe as to prevent adequate abduction and flexion of the hips for $\omega$ a surgical approach in another. I have only advised against operation on 3 other occasions, ir and these were cases where the patients' age and $\mathrm{f}$ debility would have prevented their leading a life $ᄋ$ of any activity even if the prolapse were cured. -

Certain other symptoms deserve consideration $\bar{z}$ owing to the frequency with which they are encountered. Bleeding from chronic cervicitis, $\frac{\Phi}{3}$ cervical polyp and, particularly, from ulceratio of the vaginal vault due to the prolonged use of a ring not infrequently cause the general prae $\overrightarrow{0}$ titioner to refer the case as one of post-menopaus of bleeding and possible malignant disease. Senit atrophy of the uterus predisposes to the condition of prolapse and is often accompanied by senile vaginitis with an atrophic vaginal mucous membrane, calling for treatment with oestrogens prior $\frac{\circ}{\not}$ to operation. One other symptom I have particularly noticed to be misleading; the soreness and swelling resulting from infection of the vagina with trichomonas vaginalis has resulted in not a few patients being told that they require operative treatment for prolapse when suitable local treatment will soon clear up their symptoms without any resort to surgery.

\section{Operative Technique}

The patients are usually admitted to the ward in the afternoon or evening two days before operation so that they have two nights and one day to accustom themselves to their surroundings. Preparation, apart from routine procedures of $N$ cleanliness, shaving, enema, etc., consists of a $N$ preliminary antiseptic douche, after which a swab $\mathcal{D}^{\circ}$ soaked in $a r$ in a $I, 000$ solution of flavine is left $\omega$ in the vagina. Only in cases where there has been severe and obviously infected ulceration or $\stackrel{\circ}{\subset}$ gross oedema from procidentia has any longer $\stackrel{\oplus}{\Phi}$ preparation been undertaken.

The operative procedure adopted follows the 
principles of the Manchester type of operation simplified to the utmost degree so that in the majority of cases the operation is not unduly prolonged and the duration of the anaesthetic and the degree of shock caused to the patient is cut down to the minimum-a point of importance when it is remembered that the majority of the patients are not ideal subjects for operation. The presence of three assistants, at least two of whom are trained in the procedure to be adopted, greatly facilitates the rapid performance of the operation.

Preliminary dilation of the cervix and curettage is carried out when there is any history of irregular bleeding or where the age and parity of the patient make carcinoma of the body of the uterus a possibility, but not otherwise. A triangular area of the anterior vaginal mucous membrane is removed, the shape of this triangle varying with the degree of prolapse and cystocoele present. The cervix is amputated and descending cervical branches of the uterine artery ligated on either side. The posterior lip of the cervix is reconstituted and covered with mucous membrane by three interrupted sutures, the centre one of which draws the mucous membrane into the entrance of the cervical canal. The remains of the cardinal ligaments, previously marked by tissue forceps, and the mucous membrane, are brought together from either side to support and cover the anterior lip of the cervix by two interrupted sutures; the anterior colporrhaphy is completed by a single continuous catgut suture inserted with deep bites so that a firm hold is obtained of the mucous membrane and underlying musculo-fascial tissue on either side.

The posterior colporrhaphy is carried out by excision of a triangular area of mucous membrane from the posterior vaginal wall, the base of the triangle being at the perineum; the length of the incision at the base of the triangle depends on the degree of deficiency of the perineum, while the distance to which the apex of the triangle is taken up the posterior wall depends on the degree of rectocoele and vault prolapse which is present. When this has been done the perineal muscles, particularly the levatores ani, are exposed and interrupted sutures, usually three, are inserted to bring them together in the midline. The mucous membrane of the posterior vaginal wall is then brought together by a single continuous suture, the underlying muscular stitches being tied as their level is reached coming down the posterior vaginal wall. The operation is completed by a few interrupted sutures of finer catgut to bring together the mucles and skin of the perineal body. Finally a swab soaked in flavine and paraffin is inserted into the vagina to prevent adhesions between the anterior and posterior suture line.

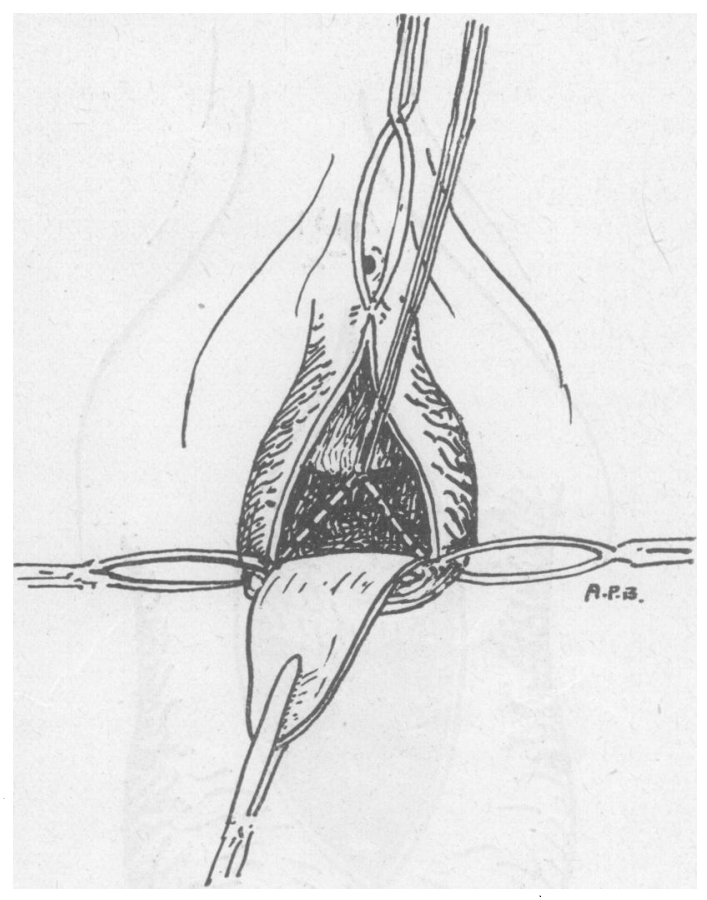

FIG. ra.-Amputation of the anterior lip of the cerviv only. After reflexion of the flap of anterior vagines mucous membrane, the upper limit of the wedge to be excised from the denuded anterior lip bein marked with a guiding suture.

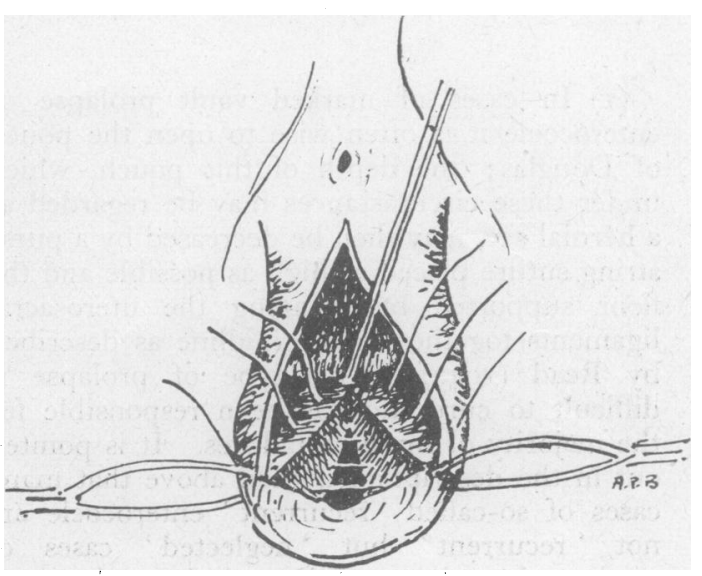

Fig. $x$ b.-After removal of the wedge from the anterior lip of the cervix.

This routine procedure is modified in three ways according to circumstances: 


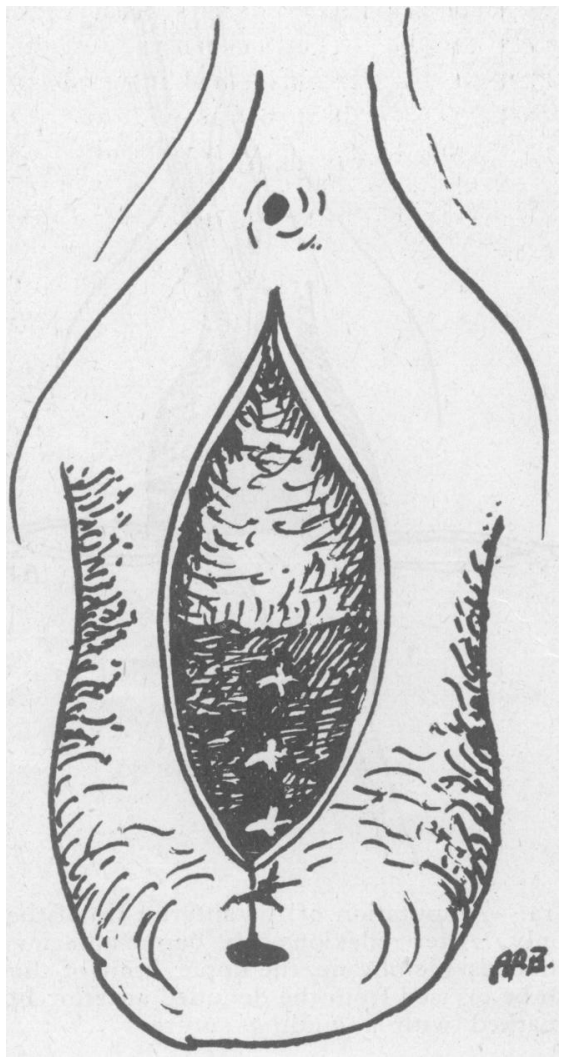

Fig. Ic.-After repair of the cervix, ready to proceed with the anterior colporrhaphy.

(I) In cases of marked vault prolapse or enterocoele it is often wise to open the pouch of Douglas; the depth of this pouch, which under these circumstances may be regarded as a hernial sac, may then be decreased by a purse string suture placed as high as possible and the floor supported by bringing the uterosacral ligaments together in the midline as described by Read (1949). This type of prolapse is difficult to cure and has been responsible for the majority of my own failures. It is pointed out in the description quoted above that many cases of so-called ' recurrent' enterocoele are not ' recurrent' but ' neglected' cases of enterocoele and a careful watch for such a condition and the adoption of the above procedure has resulted in definitely improved results.

(2) In cases where cystocoele or laxity of the anterior vaginal wall is present without any marked uterine prolapse, complete amputation of the cervix is technically difficult and often seems unnecessary, but an anterior colporrhaphy alone elevates the bladder and anterior vagina wall without corresponding elevation of the 3 cervix; the uterus often remains in its original vertical or retroverted position and is not ${ }^{-}$ anteverted as it should be when Fothergill's operation has been well carried out. Indeed $\overline{0}$ when anterior colporrhaphy alone has been completed, the cervix often looks more pro $\overline{\bar{n}}$ lapsed than it did before, owing to the elevation of the anterior vaginal wall.

Under these circumstances a wedge-shapedes area is excised from the anterior lip of the cervix so that the remains of the cardinal ligaments may be brought together in front of the cervix as they are when it has been whollyo amputated. This results in a tidy repair of the cervix, which is so often lacerated and erode although it is not markedly prolapsed, and it is elevated and restored to its natural relationshipw with the repaired anterior vaginal wall (Fig. $\mathbf{I a}_{i \mathrm{i}}$ $b$ and $c)$.

(3) In cases of marked stress incontinences unaccompanied by any very significant cysto-? coele or prolapse, a more through dissection is made exposing muscular tissue lateral to the urethra and bladder neck. These structures are then elevated by two or three buried sutues: before the anterior colporrhaphy is completed

In this series of cases vaginal hysterectomy a repair has only been carried out where there some associated abnormality of the uterus, making its removal desirable. In cases where this seemede likely to be technically difficult owing to little uterine descent, I have had no hesitation in removing the uterus per abdomen after the neces sary repair had been carried out from belowo This double operation does not seem to be followed by any undue shock provided the repair is carried out simply and rapidly as described. (Since. reading of the operation of ' abdominal colpor윽 raphy,' as described by MacLeod (1952), this double operation has been avoided on severa 5 occasions with results which at present seem completely satisfactory. It is perhaps worthy of note that four cases of moderately severe stres incontinence, together with other uterine symp toms, appear to have been completely cured bo this procedure.)

Worry about the possibility of a further preg $N$ nancy not infrequently interferes with the com plete restoration of physical and mental well-being which might be anticipated after a successfuw operation for prolapse. In cases where the mothes is already overburdened with the responsibility of a large family or where there is some associated medical abnormality to contraindicate further ${ }^{+}$ pregnancies in addition to the contraindication of 
the risk of a recurrence of the prolapse after a further pregnancy, sterilization may well be advisable. (In this series a history of severe varicose veins, often accompanied by thrombophlebitis, was a common additional contraindication to further pregnancy.) Where there is marked descent of the uterus, it may be an easy matter to open the peritoneum at its reflection from the bladder to the uterus and excise a portion of both fallopian tubes from below; where there is not enough prolapse to make this an easy procedure it takes very little longer, and causes much less anxiety to the surgeon, to complete the repair in the usual way and then excise a portion of both fallopian tubes per abdomen; adequate peritonealization of the ends of the tubes is much more easily achieved when this is done.

Having seen the extreme discomfort caused by prolapsed piles during convalescence after operation for prolapse, I could not believe that it could be any worse if haemorrhoidectomy was carried out at the same time; I now follow the repair operation by haemorrhoidectomy in all cases where severe prolapsed piles are present; the discomfort to the patient seems to be very little greater than after posterior colpo-perineorrhaphy and the results encourage me to continue with this practice.

The relative frequency with which the various procedures described have been employed is illustrated in Table $\mathbf{I}$.

\section{TABLE I}

No. of

patients

$\begin{array}{llllll}\text { Routine procedure } & \ldots & \ldots & \ldots & \ldots & 252\end{array}$

Routine procedure with amputation of anterior lip of cervix only

Anterior Colporrhaphy only (usually including amputation of anterior lip of cervix)

Posterior colpo-perineorrhaphy only (usually combined with repair of third-degree tear) ..

Urethroplasty only

Repair and subtotal hysterectomy $\quad \ldots \quad$.

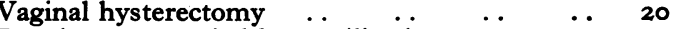

Repair accompanied by sterilisation:

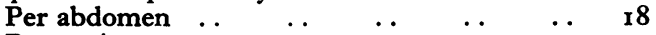

$\begin{array}{lllllll}\text { Per vaginam } & \ldots & \ldots & \ldots & \ldots & \ldots & 18\end{array}$

Repair accompanied by haemorrhoidectomy .. 12

D. \& C. and repair followed by X-ray menopause

\section{Post-Operative Complications}

The principles of the post-operative regime in these cases are, in the first place, to secure physical and mental rest for the patient, which includes the relief of pain, until healing is complete; secondly to encourage the re-establishment of normal function of the bladder and bowel and, thirdly, to encourage clean healing of the wound by such means as hot baths and douches.

The patients are encouraged to get up for a short time on the third day and by the end of a week they are helped into a bath; thereafter bed-pans can be dispensed with. Although the patient is on her feet for short intervals from an early stage, a full three weeks in hospital is considered essential and, so far as possible, arrangements are made so that they do not have to return to full household duties for two weeks after their discharge.

The patient is encouraged to pass her water naturally from the start, but if she is unable to do so, a catheter must be passed every eight hours until one is satisfied that the bladder is being properly emptied. In spite of the utmost care, a urinary infection is very common and, for this reason, prophyllactic treatment with a suitable form of sulphonamide is given as a routine for the first five days. It is striking that, when these cases are treated as a routine by a nursing staff accustomed to dealing with cases of prolapse, natural micturition is established much sooner than when only an occasional case is dealt with. Early rising is also a help in this respect.

With such treatment, complications are unusual and the convalescence may be expected to be smooth. An analysis of the complications encountered in this series is given in Table 2 . There was one death from pulmonary embolism? Moderately severe secondary haemorrhage requiro ing packing of the vagina was encountered on occasions. Further treatment for cystitis aftef the routine prophylactic treatment was complete was required in 12 cases and a febrile reaction attributed to chest complications was encountered I8 times, but in all cases was rapidly overcome with treatment with penicillin; in only a small proportion of these cases were the physical signs sufficiently well defined to warrant a diagnosis of broncho-pneumonia. In only one case did the patient's immediate post-operative condition give rise to grave anxiety; this may have been due to excessive blood loss at the time of operation or to the use of intravenous pethidene during the anaesthetic. Recovery was normal after blood transfusion.

Table 2. Post-Operative Complications

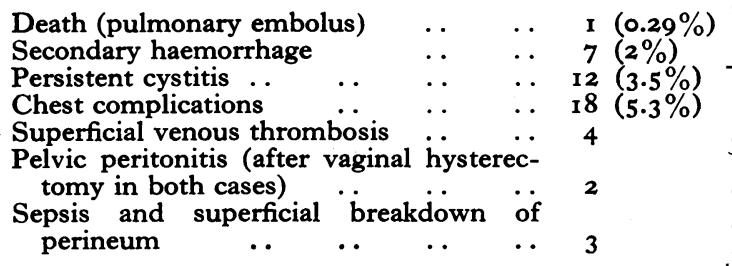

\section{Results}

In an attempt to assess the results of the treatment described, a personal letter and questionnaire was sent to each of the $34^{\circ}$ patients, all of 
whom had their operation at least one year before. In the first question they were asked if they regarded the operation as a complete success; the remaining questions related to any recurrence of the sensation of something coming down and to micturition symptoms. Every patient whose answer to the first question was other than 'yes' was sent an appointment to be seen again by myself.

Table 3. Results

Number traced: 318

Satisfactory result: $280(88 \%)$

Patient regards operation as a complete success $\ldots$
Patient's complaint unrelated to prolapse

and result satisfactory on examination ..

66

\begin{tabular}{|c|c|c|c|}
\hline \multirow{2}{*}{\multicolumn{4}{|c|}{$\begin{array}{lc}\text { Unsatisfactory result: } & 3^{8}(12 \%) \\
\text { Death (pulmonary embolus) } & \ldots\end{array}$}} \\
\hline & $\ldots \quad \ldots$ & $\mathbf{I}$ & \\
\hline Recurrence of cystocoele $\ldots$ & & 3 & \\
\hline $\begin{array}{l}\text { Recurrence of vault prolapse } \\
\text { rectocoele }\end{array}$ & or high & & \\
\hline Troublesome stress incontinence & & 8 & \\
\hline Dyspareunia $\quad \ldots \quad \ldots$ & $\cdots$ & 4 & \\
\hline Pyometra $\quad$. & $\ldots$ & $\mathbf{I}$ & \\
\hline $\begin{array}{l}\text { Patient did not regard operation } \\
\text { plete success and did not a }\end{array}$ & $\begin{array}{l}\text { as a com- } \\
\text { ttend for }\end{array}$ & & \\
\hline her examination & - & 10 & \\
\hline
\end{tabular}

The results of this enquiry are summarized in Table 3. Twenty-two patients could not be traced (three of these are known to have died subsequently from an unrelated cause). These patients were omitted from the survey. Two hundred and fourteen patients regarded the operation as a complete success (many of these added a touching word of gratitude, including one who hoped that the surgeon would have a long life and be spared to carry out this operation for many year's to come !). Sixty-six of the patients who did not regard the operation as a success were seen again; a small proportion of these had to be classed as failures; the great majority had complaints which were unrelated to prolapse; carcinophobia, functional uterine haemorrhage or just a desire to be reassured that everything was going on all right accounted for the greatest number. A complaint of persistent backache, often due to visceroptosis and relieved by a surgical belt, was not classified as an unsatisfactory result unless it was thought to be due to recurrent prolapse or retroversion after examination. Ten patients who did not regard the operation as a success but failed to. attend for further examination were included in the number of unsatisfactory results. An unsatisfactory result was found in 38 cases ( 12 per cent.). In analyzing these unsatisfactory results a localized recurrence of cystocoele was found on three occasions.
These were possibly attributable to the use of single continuous suture for the anterior colpor rhaphy; the incidence is small (less than I pe? cent.) and all three cases have been cured by further relatively minor operation. The risk frono the use of a single continuous suture therefore seems to be slight and is more than outweighe by the low incidence of post-operative complica $\overline{\bar{s}}$ tions which must be partly due to the ease an rapidity of operation, especially in elderl patients.

A recurrence of some degree of vault prolaps $\vec{\theta}$ or high rectocoele in II cases (3.4 per cent.) is disappointing. In two cases the patient was quite unconscious of the recurrence. No treats ment is considered necessary at the present time but they are being kept under observation in cast. the condition gets worse. Five patients, all of whom had a complete procidentia of many years standing say that they have been completely freer from symptoms since they were fitted with \& small ring when the recurrence was recognizedo Two cases have undergone further operation with results which at present appear satisfactory an $\phi$ two are still waiting for this to be done. Over hale of these recurrences were in patients of over sixts who had a complete procidentia prior to operationd This point is considered further in the discuss $8 n^{-}$ of the results of procidentia (vide infra).

The total number of recurrences, cystocode rectocoele or vault prolapse, is therefore $14(7 ?$ per cent.). It is of interest that, with one exceps tion, all these recurrences occurred within six months of operation.

One patient complained of attacks of abdomina年 pain and intermittent dark brown discharge Examination revealed a pyometra from stenosis of the cervical canal. Total hysterectomy was undertaken, owing to the difficulty of excluding carcinama of the body of the uterus, and the patient is in good health.

The figure of only four cases of dyspareunia is probably inaccurate. Enquiry regarding this point was not included in the original question? naire because, knowing some of the patients in this area, I felt sure that it would prevent a certairo number from replying at all. All the patients who were seen again were questioned about this point and difficulties were only encountered in four. In a small proportion of more elderlyo patients with marked vault prolapse, the vaginat vault was deliberately overnarrowed; these patientsu were told that complete intercourse might $b \varepsilon_{\delta}^{\omega}$ impossible after operation and so might not complain of it afterwards. Although the incidence् of this difficulty is almost certainly higher thans appears from these figures, I have formed the opinion that it is a relatively rare complications 
when the posterior repair has been carried out with due care.

Further information can be gained from these results if they are analyzed with reference to certain of the presenting symptoms:

Stress incontinence was present in 132 patients (39 per cent.) when they were first seen. This condition was cured in 68 per cent. and greatly improved in a further 26 per cent. The results are summarized in Table 4.

Table 4. Results-Stress Incontinence

Number of patients with an initial complaint of stress incontinence $\quad \ldots \quad \ldots \quad \ldots \quad \ldots \quad 132(39 \%)$ $\begin{array}{llllll}\text { Number traced } & \ldots & \ldots & \ldots & \ldots & 123\end{array}$ Cured according to their own statement $84(68 \%)$ Still slight stress incontinence .. $\quad . . \quad 31(26 \%)$ Still severe stress incontinence ... $\quad . . \quad 8$ (6\%)

Number of patients with severe stress incontinence unassociated with prolapse Cured according to their own statement and no stress incontinence demonstrated on examination

Still slight stress incontinence after plastic operation from below (urethroplasty). . 17 I I $(65 \%)$ $3(17 \%)$ Still severe stress incontinence $3(17 \%)$

Complete procidentia was encountered in $4 \mathrm{I}$ cases. This was treated by the Manchester type of operation on 39 occasions, which included opening and decreasing the depth of the pouch of Douglas and securing the uterosacral ligaments on five occasions. Examination of the results shows that some degree of persistent enterocoele was present in four cases (10 per cent.). Two other cases were unsatisfactory, one being one of the three cases of recurrent cystocoele previously mentioned, and one developing a pyometra. Two cases were treated by vaginal hysterectomy with satisfactory results. These results are disappointing and indicate the importance of looking for the associated enterocoele and dealing with it adequately. To my mind the results do not indicate the routine employment of vaginal hysterectomy except in those cases where this procedure is necessary to obtain adequate exposure and support for the floor of the pouch of Douglas.

Table 5. Results-Complete Procidentia

\begin{tabular}{|c|c|c|c|}
\hline & & Satisfactory & Unsatisfactory \\
\hline Number of cases & 4I & $35(85.36 \%)$ & $6(14.66 \%$ \\
\hline Routine operation & 34 & 30 & 4 \\
\hline $\begin{array}{c}\text { Routine operation } \\
\text { plus opening pouch }\end{array}$ & & & \\
\hline $\begin{array}{l}\text { of Douglas, etc. . } \\
\text { Vaginal hysterec- }\end{array}$ & 5 & 3 & 2 \\
\hline tomy & 2 & 2 & 0 \\
\hline
\end{tabular}

Examination of the age incidence shows that operation was undertaken at the age of seventy or over in 13 cases. Six of these suffered from longstanding complete procidentia and were only driven to seek advice because they could no longer get about or because of bleeding from ulceration of the prolapsed mucosa. In none of these cases was there any serious post-operative complication; in II the results were completely satisfactory; in two there was a slight persistent enterocoele (already included in the unsatisfactory results of operation for complete procidentia). Both of the latter were rendered completely free of symptoms by fitting a small ring.

TABle 6. Results-Age InCidence OF OVER 70

Number of cases ... $\quad \ldots \quad \ldots \quad \ldots \quad \ldots \quad$ I3

Results: Completely satisfactory $\quad \ldots \quad \ldots \quad$ I I Marked improvement .. $\quad \ldots \quad \ldots \quad 2$

\section{Discussion}

The fact that 88 per cent. of the patients were satisfactorily cured of their prolapse is gratifying, but consideration of the remaining 12 per cent. shows that there is room for improvement.

Fletcher Shaw (1934) advocating the employment of an operation, the principles of which are very similar to those here described, for all types of prolapse, reports 98.36 per cent. of 664 cases ' completely cured.' On the other hand, Stallworthy (1940), in a very careful study of $268^{\circ}$ cases operated upon by different surgeons, reports a recurrence rate of 13 per cent. (a quarter of these being after a further pregnancy). In addition to this, ro per cent. suffered from severe stress incontinence and ro per cent. from dyspareunia.

It is in cases of complete procidentia and enterocoele that opinions differ most, and examination of the results in the present series shows there was a recurrent of some degree of enterocoele in Io per cent. Currie (1952) reports on the result of 62 cases of 'massive prolapse' treated by the Manchester type of operation with a definite recurrence in 4.8 per cent. and some bulging of the vault in a further 8 per cent.

An alternative method of treatment for this type of case is vaginal hysterectomy and repair. It is questionable whether this gives any better results unless special precautions are taken to diminish the depth of the pouch of Douglas and support the pelvic floor. Gniou (1950) reports a recurrence rate of 6 per cent. in 85 cases treated by vaginal hysterectomy, which is no great improvement on the figures given here.

The importance of enterocoele and herniation of the floor of the pouch of Douglas is clearly recognized by Veenbeer and Kooistra (1947), who describe a procedure which gives additional support to this area by utilization of the utero-sacral ligaments after vaginal hysterectomy. They report only two failures in 104 cases. 
The observations of Read on this point have already been mentioned (Read, I949). In a series of 139 cases, all of whom were operated upon specifically for enterocoele (many of them after previous repair procedures), there was a recurrence in only one, and 9I per cent. of the patients traced were cured and symptom-free. Vaginal hysterectomy was employed in a very small per centage of these cases. It would seem that recognition and adequate treatment of the enterocnele is the secret of success whether the uterus is removed or not.

A second alternative in the treatment of these cases of severe prolapse with associated prolapse of the vaginal vault is the employment of Le Fort's operation. In view of the very satisfactory mortality and morbidity figures which can be achieved by the Manchester type of operation (or vaginal hysterectomy), the argument that Le Fort's operation is a less serious procedure for an elderly patient carries little weight. The obliteration of the vagina which this procedure entails could only be justified if the results were definitely superior; in fact, this does not seem to be the case. Kühnel (1952), in an analysis of $5^{8}$ cases treated in this way, reports a recurrence in 5.4 per cent. and a mortality of over 3 per cent. The difficulty of investigating and treating any subsequent uterine haemorrhage is also emphasized by Mazer and Israel (1948).

\section{Conclusions}

A repair procedure based on the principles of the Manchester type of operation may be relied upon to produce a satisfactory result in approximately 90 per cent. of cases of prolapse.

The operation is not accompanied by any grave disturbance to the patient and post-operative complications are rare. The number of patients whose age or general condition contraindicates operation is small and very few should be con- demned to the permanent use of a ring or cup and stem pessary or any similar contrivance.

Stress incontinence is cured in over 60 per $\stackrel{\mathbb{Q}}{2}$ cent. of cases and greatly improved in a further 25. per cent. There remains a small but very definite proportion in whom some more extensive pro- $-\frac{7}{0}$ cedure is necessary to relieve this complaint.

Cases of complete procidentia can be satis- $\overline{\bar{c}}$. factorily cured by the Manchester type of opera- $\vec{D}$ tion, provided that any associated enterocoele is exposed and dealt with. It is not essential to employ vaginal hysterectomy in such cases unless $\overrightarrow{0}$ adequate exposure cannot be obtained without or $\overrightarrow{-}$ there is some associated uterine disease.

The purpose of this investigation has been to examine and endeavour to improve upon my own $\frac{0}{3}$ results. No new principles have been described or new arguments put forward. If it should. stimulate others to look into their own results $\omega$ with a critical eye, its purpose will have been is doubly achieved.

My thanks are due to Mr. Aubrey Good. o Mr. Charles Read and Miss Hetty Player (late theatre sister at Chelsea Hospital for Women), $\vec{z}$ who gave me the instruction and courage which was necessary in the beginning; to the theatre $\frac{\Phi}{3}$ and ward staff at the Norfolk and Norwieng Hospital and the Wayland Hospital, Attleborough, whose co-operation has made the work a pleasue; $\overrightarrow{0}$ and to my patients for the gratification of satis factory results and the stimulation to improvement where the results have been otherwise.

\section{BIBLIOGRAPHY}

CURRIE, D. W. (1952), F. Obstet. Gyn. Brit. Emp., 59, 96. GNIOU, N. M. (1950), Canad. Med. Ass. F., 63, 147.

JEFFCOATE, T. N. A. (1949), Ұ. Obstet. Gyn. Brit. Emp., 59, 685. KUHNEL, P. (1952), Acta. Obstet. Gyn. Scand., 31, 151 .

MACLEOD, D. (1952), F. Obstet. Gyn. Brit: Emp., 58, 583.

MAZER, C., and ISRAEL, S. L. (1948), Amer. F. Obst. Gyn., 56,

READ, C. D. (1949), ' Trans. XIIth Brit. Cong. Obst. Gyn.,' p. 189

SHAW, W. F. (1934), F. Obstet. Gyn. Brit. Emp., 41, 853.

STALLWORTHY, J. A. (1940), Ibid., 47, 391.

\section{RUTHIN CASTLE, NORTH WALES}

A Clinic for the diagnosis and treatment of Internal Diseases (except Mental or Infectious Diseases). The Clinic is provided with a staff of doctors, technicians and nurses.

The surroundings are beautiful. The climate is mild. There is central heating throughout. The annual rainfall is 30.5 inches, that is, less than the average for England.

The Fees are inclusive and vary according to the room occupied.

For particulars apply to THE SECRETARY, Ruthin Castle, North Wales. 